\title{
Erratum to: Increasing the Efficiency of the Multi-mission Radioisotope Thermoelectric Generator
}

\author{
TIM C. HOLGATE, ${ }^{1,3}$ RUSSELL BENNETT, ${ }^{1}$ TOM HAMMEL, ${ }^{1}$ \\ THIERRY CAILLAT, ${ }^{2}$ STEVE KEYSER,${ }^{1}$ and BOB SIEVERS ${ }^{1}$ \\ 1.-Teledyne Energy Systems, Inc. (TESI), Hunt Valley, MD 21031, USA. 2.-Jet Propulsion \\ Laboratory, California Institute of Technology, Pasadena, CA 91109, USA. 3.-e-mail: \\ Tim.holgate@teledyne.com
}

\section{Erratum to: Journal of ELECTRONIC MATERIALS, Vol. 44, No. 6, 2015, pp. 1814-1821 \\ DOI 10.1007/s11664-014-3564-9}

On page 1816 in the original article, ninth line in the left column, the corrected formulas are as follows:

$(\mathrm{Ba}, \mathrm{Yb})_{x} \mathrm{Co}_{4} \mathrm{Sb}_{12}$ and $\mathrm{Ce}_{x}(\mathrm{Fe}, \mathrm{Co})_{4} \mathrm{Sb}_{12}$. 